Article

\title{
Does Arbuscular Mycorrhiza Determine Soil Microbial Functionality in Nutrient-Limited Mediterranean Arid Ecosystems?
}

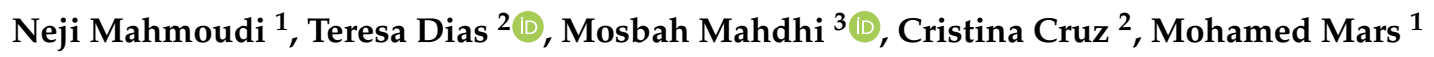 \\ and Maria F. Caeiro ${ }^{4} *$ (D) \\ 1 Unité de Recherche Biodiversité et Valorisation des Bio-ressources en Zones Arides (BVBZA), \\ Faculté des Sciences de Gabès, Cité Erriadh Zrig 6072, Tunisie; neji.2012@yahoo.com (N.M.); \\ Mohamed.Mars@fsg.rnu.tn (M.M.) \\ 2 Centre for Ecology, Evolution and Environmental Changes (cE3c), Faculdade de Ciências da Universidade \\ de Lisboa, Edifício C2, Piso 5, Sala 2.5.03 Campo Grande, 1749-016 Lisboa, Portugal; mtdias@fc.ul.pt (T.D.); \\ cmhoughton@fc.ul.pt (C.C.) \\ 3 Center for Environmental Research and Studies, Jazan University, Jazan-P.O. Box 114, Jazan 82817, \\ Saudi Arabia; mmahdhi@jazanu.edu.sa \\ 4 Centro de Estudos do Ambiente e do Mar (CESAM), Faculdade de Ciências da Universidade de Lisboa, \\ Edifício C2, Piso 2, Campo Grande, 1749-016 Lisboa, Portugal \\ * Correspondence: mfcaeiro@fc.ul.pt
}

Received: 5 May 2020; Accepted: 4 June 2020; Published: 10 June 2020

check for updates

\begin{abstract}
Arbuscular mycorrhizal fungi (AMF) are determinant for the performance of plant communities and for the functionality of terrestrial ecosystems. In natural ecosystems, grazing can have a major impact on mycorrhizal fungi and consequently on plant growth. The objective of this study was to evaluate the statements referred above in Mediterranean arid areas in Tunisia. Root samples and rhizosphere soils of five dominant herbaceous plants were studied at six distinct arid sites differing on soil proprieties and grazing intensity. At each site, chemical and dynamic properties of the soil were characterized as well as the AMF colonization intensity and the soil functionality. Results showed that the mycorrhizal frequency and intensity and spore density, varied between plants in the same site and, for each plant, between sites and evidenced a positive effect of mycorrhized plants on soil microbial activity. Grazing and soil properties strongly affected AMF composition and the soil microbial and biochemical dynamics, which presented the lowest values at the sites with the highest grazing intensities. In conclusion, these results demonstrate that AMF improve soil biological properties, supporting the hypothesis that mycorrhiza and grazing compete for plant photosynthates, and highlight the importance of mycorrhizal symbiosis towards soil functionality under arid conditions.
\end{abstract}

Keywords: arbuscular mycorrhizal fungi; arid areas; biological properties; conserved areas; grazing; mycorrhiza

\section{Introduction}

Arid and semi-arid regions of the world are considered as being particularly vulnerable to climate change [1]. They are already climatically stressed with high temperatures, low rainfall and long dry seasons. These ecosystems are highly dynamic, with bursts of productivity in the wet season of some years, and very low productivity in dry years. The arid and semi-arid regions of the world have been subjected to accelerated desertification due to increasing grazing intensity, decreased rainfall, higher temperatures and prolonged periods of drought $[2,3]$. These pressures, associated with increased 
anthropogenic impacts and climate changes, caused the decline of forests, regression and extinction of many pastoral and forage species, and accelerated soil degradation and change of soil microbial communities [1].

In most cases, the degradation process starts with the disruption of functional networks that protect and alleviate stress, conferring to the organisms involved protection to global changes [4], including land use changes. Plants are well known for their symbioses with nitrogen fixing bacteria and arbuscular mycorrhiza fungi (AMF). These are just two examples of a vast range of symbiotic relationships that consist the plant microbiome and modulate plant phenotype and, thus, plant fitness. In this context, the microbial community of the rhizosphere [5] is of great importance to plant performance, playing a crucial role in ecosystem functioning. The microbial activities of the rhizosphere also determine the bioavailability of nutrients and, therefore, soil fertility. Plants interact with guilds of these beneficial microorganisms living in their rhizosphere, promoting their growth and development [6].

Arbuscular mycorrhiza involves reciprocal complementary resource exchanges between plant roots and soil fungi and is widespread in natural ecosystems [7]. When colonizing the roots, AMF develop intra- and extra-radical mycelium. The hyphae of the intra-radical mycelium colonize the cells of the root cortex and penetrate the periplasmic space where they develop vesicles and arbuscules that are the structures responsible for most of the exchanges between the fungi and the plant $[8,9]$. The extra-radical mycelium spreads its hyphae beyond the root surface and colonizes the surrounding substratum, increasing the volume of soil explored, and creating a privileged space for microbial development. As part of the interaction, the host plant provides the fungus with carbon in exchange for nutrients and water is taken up by the fungus $[8,10]$. Thus, mycorrhiza plays a crucial role in terrestrial ecosystem functioning, especially in arid or semi-arid areas, where root exudates are the major carbon source supporting soil microbial activities [11]. Apart from the nutritional benefits, mycorrhization tend to increase plant tolerance to other stress (biotic and abiotic) conditions [12].

Despite the major ecological importance of AMF, there is a lack of knowledge on the effect of AMF on soil microbial properties and biological activities, or the effect of ecosystem management (including grazing) on mycorrhization. The complex herbivore-plant-AMF is dependent on the species involved in these interactions, the intensity and frequency of grazing, vegetation, and topography $[13,14]$. Some studies indicate that grazing influences soil biochemical activity, usually through the degradation of soil structure by trampling [15] and the imbalance of soil chemical, microbial and biochemical properties [16].

There is limited information about the effects of grazing on AMF communities and on soil microbial composition and function, especially for low fertility soils, as found in most Mediterranean arid and semi-arid regions. This work addressed both questions in three arid and semi-arid regions of Tunisia, by evaluation of grazing intensity on AMF-plant interactions, and the consequent impact on soil microbial communities.

\section{Materials and Methods}

\subsection{Study Site}

This study was developed at three conserved natural areas (Figure 1) in the arid and semi-arid ecosystem of Tunisia, under Mediterranean climate: Bou-Hedma National Park (Sidi Bouzid coordinates, $34^{\circ} 39^{\prime} \mathrm{N}, 94^{\circ} 8^{\prime} \mathrm{E}$ ), Zarat-Gabes protected area (Gabes coordinates, $33^{\circ} 41^{\prime} \mathrm{N}, 10^{\circ} 23^{\prime} \mathrm{E}$ ) and Oued Dkouk Natural Reserve (Tataouine coordinates, $32^{\circ} 37^{\prime} \mathrm{N}, 10^{\circ} 18^{\prime} \mathrm{E}$ ). The annual temperature range is very high in these areas, with minimal and maximal monthly temperature means of $17^{\circ} \mathrm{C}$ (January) and $36^{\circ} \mathrm{C}$ (August), respectively. The mean annual rainfall in these ecosystems varies between 100 and $260 \mathrm{~mm}$. 


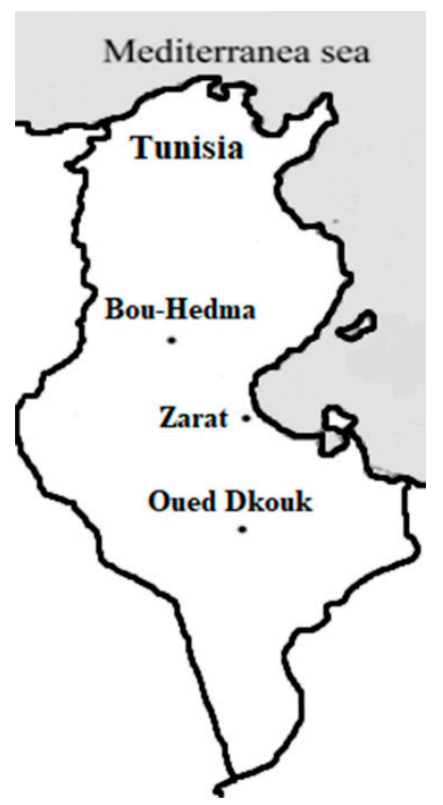

Figure 1. Location of the three conserved natural areas in the arid Mediterranean ecosystem of Tunisia.

Experiments were carried out in three natural protected areas of Tunisia (Bou-Hedma, Zarat, and Oued Dkouk) (Table 1). At each natural park samples were taken in two sites, one inside and the other outside the protected area. The studied sites differed in grazing intensity and soil type (Table 1). The three sites inside the conserved areas were subjected to a light grazing, while the other three sites outside were subjected to more intensive grazing by domestic herds of sheep, goats and camels.

Table 1. Details of the six sampling sites at the three conserved natural areas.

\begin{tabular}{ccccc}
\hline \multicolumn{2}{c}{ Conserved Areas } & Site & Vegetation Type & Grazing Intensity \\
\hline \multirow{2}{*}{ Bou-Hedma } & inside & 1 & Acacia spp. and spontaneous herbaceous plants & Light \\
& outside & 2 & Cultivated and spontaneous herbaceous plants & Intensive \\
\hline \multirow{2}{*}{ Zarat } & inside & 3 & Acacia spp. and spontaneous herbaceous plants & Light \\
& outside & 4 & Cultivated and spontaneous herbaceous plants & Intensive \\
\hline \multirow{2}{*}{ Oued Dkouk } & inside & 5 & Spontaneous herbaceous plants & Light \\
& outside & 6 & Spontaneous herbaceous plants & Intensive \\
\hline
\end{tabular}

\subsection{Roots and Soil Sampling}

Five plant species (common to all study sites) and three plants per species per site were analyzed for AMF colonization. The herbaceous plants collected were: Lotus creticus (Fabaceae), Medicago truncatula (Fabaceae), Astragalus corrugatus (Fabaceae), Malva aegyptiaca (Malvaceae), Diplotaxis simplex (Cruciferacea).

Plant roots were carefully collected in order to access the fine active roots where mycorrhiza colonization occurs. Simultaneously, rhizosphere soil of each plant was also collected. For each site, a pooled soil sample (composed of 5 soil cores with $10 \mathrm{~cm}$ diameter and $20 \mathrm{~cm}$ length) was collected in an area without vegetation and used as a control (bulk soil) for the influence of the plant in the dynamic soil characteristics. Soils were sieved $(2 \mathrm{~mm})$ to remove the remains of plants, gravel and earthworms, and stored at $4{ }^{\circ} \mathrm{C}$ for further analysis. Soil samples were analyzed in triplicates.

\subsection{AMF Colonization Status}

According to the methods of Phillips and Hayman [17], AMF colonization was evaluated after observation of 30 root fragments per plant. Of each plant species, root segments $(1-2 \mathrm{~cm} \mathrm{length)}$ were submerged in $10 \%$ potassium hydroxide $(\mathrm{KOH})$ at $90{ }^{\circ} \mathrm{C}$ for $45 \mathrm{~min}$. After bleaching and 
acidification steps with hydrogen peroxide $\left(\mathrm{H}_{2} \mathrm{O}_{2}\right)$ and hydrogen chloride $(\mathrm{HCl})$, respectively, root pieces were colored with $1 \%$ Trypan Blue solution. The duration of each step varied among plant species, according to the respective root diameter and surface root characteristics. For each plant species from each site, 30 root fragments were placed on slides and preserved with lactoglycerol. In all the stained roots, the presence of hyphae, vesicles, and arbuscules inside the root were viewed through a microscope (Nikon, Tokyo, Japan) at 400× magnification. The frequency (F\%): number of colonized roots/total number of observed roots) and intensity of mycorrhization ( $\mathrm{M} \%$ ): proportion, in percentage, of the root colonized by AMF) were calculated using the Mycocalc program (http://www2.dijon.inra.fr/mychintec/Mycocalcprg/download.html)

\subsection{Quantification of AMF Spore Density}

Using the wet sieving method from Gerdemann and Nicolson [18], AMF spores occurring in soil samples were extracted and quantified. Three nested sieves of 1000, 100, and $32 \mu \mathrm{m}$ were used. For each soil sample, quantities of $100 \mathrm{~g}$ were submerged in $1 \mathrm{~L}$ of tap water. After a stirring step, the supernatant was sieved through the nested sieves. The spores that hold on to the two sieves of 100 and $32 \mu \mathrm{m}$ were recovered in $5 \mathrm{~mL}$ centrifuge tubes. After a step of centrifugation on a viscosity gradient (sucrose solution at $60 \%$ ), the supernatant retained was rinsed with distilled water to remove the sucrose solution. Retrieved AMF spores of each soil sample were counted under a stereomicroscope (40× magnification) and average numbers were calculated per $100 \mathrm{~g}$ of dry soil.

\subsection{Soil Analysis: Physical and Chemical Properties}

Soil $\mathrm{pH}$ and electrical conductivity were determined in a 1:1 $(v / w)$ water: bulk soil suspension using a pH meter (Matest, Treviolo, Italy) and a conductivity meter (Bibby Scientific, Bibby Scientific, Staffordshire, UK), respectively [19]. Soil texture, which represents the granulometric distribution of its constituents (the proportion between small particles: clay, silt and sand), was calculated using the Robinson's pipette method [20]. The other main physicochemical soil characteristics (organic matter, total nitrogen, total phosphorus and water content) were determined by conventional analyses performed by the Soil Analysis Laboratory in the Regional Commissariat for Agricultural Development, in Gabes. The determination of the organic matter was carried out indirectly, starting from the determination of the organic carbon content of soil. The determination of total phosphorus was evaluated by a degradation acid reaction step followed by a dosing step carried out in an automated spectrophotometer (Shimadzu, Kyoto, Japan). The total nitrogen was determined following the Kjeldahl method.

\subsection{Microbiological and Biochemical Properties}

For the impact of AMF on microbiological parameters, the carbon of the microbial biomass (Cmic) present in the plant rhizosphere and bulk soil were evaluated following the "fumigation-extraction" technique [21]. This method is based on three essential steps: a fumigation step with chloroform, incubation in a 10-days fumigation period, and an extraction step with ninhydrin-N reactive and potassium chloride $(\mathrm{KCl})$. This technique has been used to provide rapid and accurate measurements of soil biomass $-\mathrm{C}$ and $-\mathrm{N}$.

To evaluate the effect of AMF on biochemical properties, alkaline phosphatase and $\beta$-glucosidase activities were calculated and evaluated according to the method of Caravaca et al. [22] in a spectrophotometer (Shimadzu, Japan) at $398 \mathrm{~nm}$. The dehydrogenase activity was determined as described by Garcia et al. [23] in a spectrophotometer (Shimadzu, Japan) at $490 \mathrm{~nm}$.

\subsection{Statistical Analyses}

Analyses of variance (ANOVA) for repeated measures using the XLSTAT (v2010.5.04) software (Addinsoft, New York, NY, USA) were ascertained to test the effect and the significant difference 
between the studied parameters. Least significant difference values at the $5 \%$ levels of significance $(p \leq 0.05)$ were calculated to assess differences between different values.

To evaluate the effects of the grazing parameter (explanatory variable) on mycorrhizal properties (F\%, M\% and number of spores) (response variables), ANOVA and Canonical Correlation Analysis (CCorA) were applied.

To evaluate the relationships between soil physical and chemical parameters and mycorrhizal properties (F\%, M\% and number of spores), a principal-component analysis (PCA) was applied.

Pearson's correlation was used to determine relationships between variables: mycorrhizal properties and microbiological and biochemical parameters.

To model the relationships between mycorrhizal properties and parameters of soil microbial and biochemical activities by linear regression, XLSTAT (v2010.5.04) software was used.

\section{Results}

\subsection{Physical and Chemical Properties of Soils}

The more resilient soil characteristics such as soil texture (Table 2) and pH did not show big discrepancies among sites inside and outside the protected areas. However, differences were obtained for the more responsive soil dynamic characteristics: electrical conductivity (E.c), total nitrogen (T.N), total phosphorus (T.P), organic matter (Org. Mat), and water content (Wat. Con). In general, the studied sites had an alkaline $\mathrm{pH}$ ranging from 8.0 to 8.4. The highest percentages of soil organic matter were observed in Site $1(2.6 \%)$ as well as inside the other protected areas. Identical patterns were observed for the total nitrogen, the highest level (194 ppm) also being observed in Site 1, followed by Sites 3 and 5 (inside the protected areas). For the total phosphorus content, it was the contrary: the highest values were registered in the sites outside the protected areas (15.3 ppm was the highest value, registered in Site 6). Water content (varying between 1.3 to 3.3\%) and electrical conductivity (ranging from 1.3 to $2.5 \mathrm{~s} \cdot \mathrm{m}^{-1}$ ) always presented the highest values in the sites inside each protected area.

Table 2. Physical and chemical properties of the six sampling sites from the three conserved ecosystems.

\begin{tabular}{|c|c|c|c|c|c|c|}
\hline \multirow{3}{*}{ Parameters } & \multicolumn{2}{|c|}{ Bou-Hedma } & \multicolumn{2}{|c|}{ Zarat } & \multicolumn{2}{|c|}{ Oued Dkouk } \\
\hline & Inside & Outside & Inside & Outside & Inside & Outside \\
\hline & Site 1 & Site 2 & Site 3 & Site 4 & Site 5 & Site 6 \\
\hline Clay (\%) & $11.0 \pm 0.2^{b}$ & $12.8 \pm 0.1^{\mathrm{a}}$ & $9.2 \pm 0.2^{d}$ & $10.2 \pm 0.1^{\mathrm{c}}$ & $6.5 \pm 0.2^{f}$ & $7.0 \pm 0.1^{\mathrm{e}}$ \\
\hline Silt (\%) & $23.5 \pm 1.1^{\mathrm{d}}$ & $26.1 \pm 0.1^{b}$ & $25.1 \pm 0.2^{c}$ & $34.7 \pm 0.3^{a}$ & $16.4 \pm 0.7^{\mathrm{e}}$ & $15.3 \pm 0.5^{f}$ \\
\hline Sand (\%) & $65.8 \pm 0.2^{c}$ & $60.0 \pm 1.2^{\mathrm{e}}$ & $64.7 \pm 1.1^{\mathrm{d}}$ & $55.0 \pm 1.4^{\mathrm{f}}$ & $77.0 \pm 1.1^{b}$ & $78.6 \pm 1.1^{\mathrm{a}}$ \\
\hline $\mathrm{pH}$ & $8.1 \pm 0.1^{b}$ & $8.1 \pm 0.1^{b}$ & $8.0 \pm 0.1^{b}$ & $8.1 \pm 0.1^{b}$ & $8.4 \pm 0.1^{\mathrm{a}}$ & $8.4 \pm 0.1^{\mathrm{a}}$ \\
\hline E.c $\left(s \cdot m^{-1}\right)$ & $2.5 \pm 0.3^{a}$ & $1.8 \pm 0.2^{\mathrm{c}}$ & $2.4 \pm 0.3^{\mathrm{a}}$ & $1.6 \pm 0.2^{\mathrm{d}}$ & $2.0 \pm 0.1^{b}$ & $1.3 \pm 0.1^{\mathrm{e}}$ \\
\hline T.N (ppm) & $191.0 \pm 23^{a}$ & $150.0 \pm 10^{d}$ & $174.0 \pm 15^{b}$ & $130.0 \pm 10^{e}$ & $160.0 \pm 10^{c}$ & $90.0 \pm 5^{f}$ \\
\hline T.P (ppm) & $7.0 \pm 0.1^{\mathrm{f}}$ & $10.6 \pm 0.2^{c}$ & $8.2 \pm 0.2^{\mathrm{e}}$ & $12.4 \pm 0.2^{b}$ & $10.0 \pm 0.2^{\mathrm{d}}$ & $15.3 \pm 0.6^{\mathrm{a}}$ \\
\hline Org. Mat (\%) & $2.6 \pm 0.2^{\mathrm{a}}$ & $1.4 \pm 0.1^{\mathrm{d}}$ & $2.0 \pm 0.1^{b}$ & $1.2 \pm 0.1^{\mathrm{e}}$ & $1.6 \pm 0.3^{c}$ & $0.8 \pm 0.1^{\mathrm{f}}$ \\
\hline Wa. Cont (\%) & $3.3 \pm 0.1^{\mathrm{a}}$ & $2.3 \pm 0.1^{\mathrm{d}}$ & $2.9 \pm 0.2^{b}$ & $2.0 \pm 0.1^{\mathrm{e}}$ & $2.5 \pm 0.1^{c}$ & $1.4 \pm 0.3^{f}$ \\
\hline
\end{tabular}

E.c: electrical conductivity; T.N: total nitrogen; T.P: total phosphorus; Org. Mat: organic matter; Wat. Con: water content. Letters a-f: significant differences $(p<0.05)$; mean and standard error values $(n=3)$.

\subsection{AMF Colonization of Plant Roots}

Three plants and 30 root fragments of each one of the five plant species were analyzed per site. Direct observation of the root samples under the microscope showed that the roots of all studied plants, except those of Diplotaxis simplex, were colonized by AMF. All the structures characteristic of root colonization by AMF (intracellular aseptate hyphae, vesicles and arbuscules) were observed. The highest mycorrhizal frequency (F\%)) was observed for $M$. truncatula in all the studied sites. At each site, the mycorrhizal frequency (F\%)) varied among the plant species (Figure 2). The plants with the highest AMF root colonization belong to the Fabaceae family (M. truncatula, A. corrugatus and L. creticus) in all the studied sites, always with higher values in the site inside each conserved area. 
There were significant differences $(p<0.001)$ in the mycorrhizal intensity $(\mathrm{M} \%)$ among sites, again with highest $\mathrm{M} \%$ for $M$. truncatula as well as, for each plant species, for the plants in the sites inside the conserved areas (Figure 2).

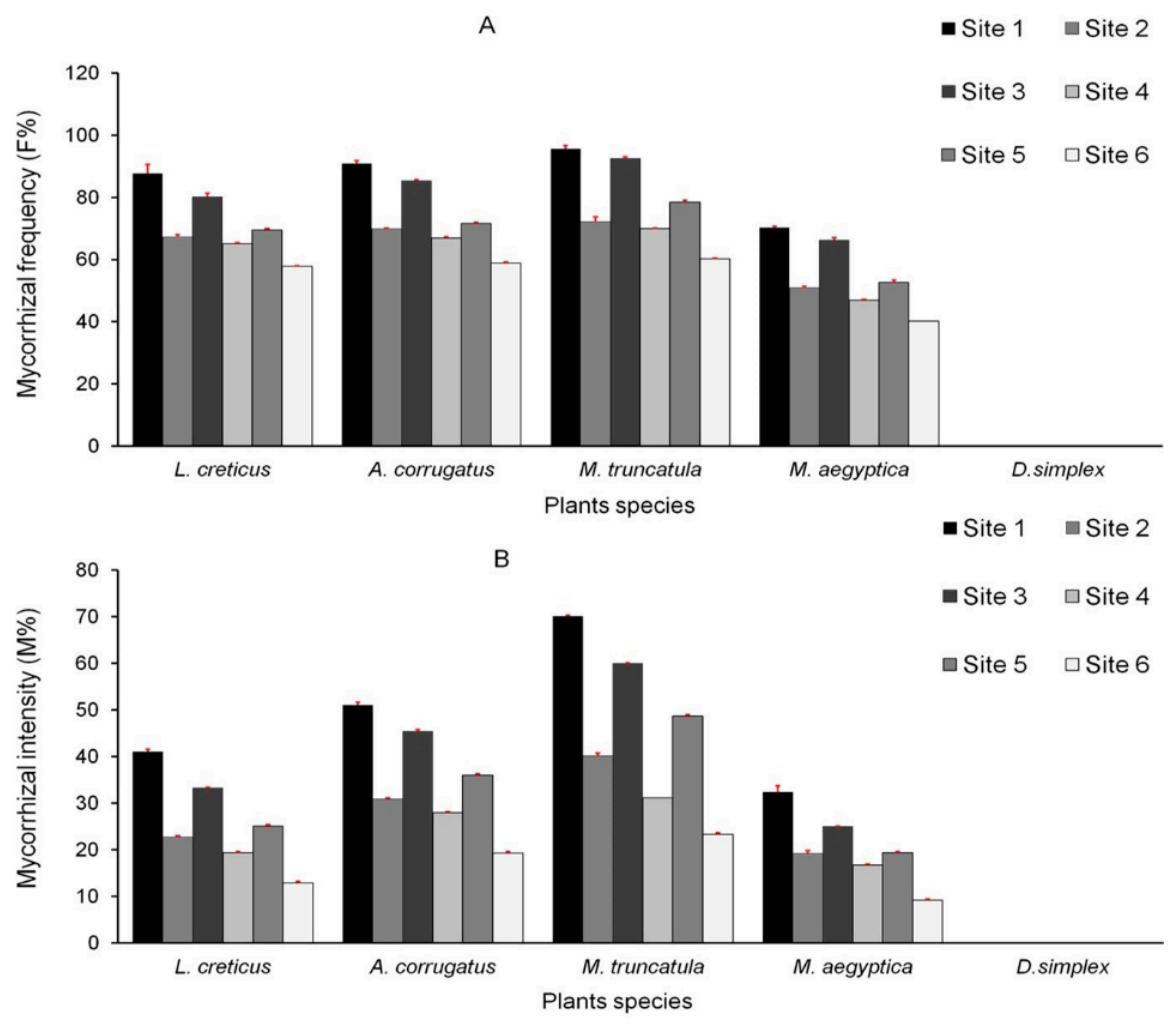

Figure 2. Mycorrhizal frequency (A) and Mycorrhizal intensity (B) of the five herbaceous plants in the different studied sites. Data are reported as mean $( \pm \mathrm{SE})$ of three replicates per sample.

\subsection{Densities of Spore Populations in the Studied Soils}

The density of AMF spores isolated from the rhizosphere of the sampled plants varied between 856 (M. truncatula) in Site 1 and 81 spores/100 g of soil (D. simplex) in Site 6 (Figure 3). Therefore, spore density varied significantly $(p<0.001)$ among the studied sites; the maximum values were recorded in the rhizosphere of plants from sites 1, 3 and 5 (inside the conserved areas and lightly grazed) and the minimum values in sites 2, 4 and 6 (outside the conserved areas and intensively grazed). Bare areas (bulk soil), followed by D. simplex rhizosphere soil, always presented the lowest values for the six sites (Figure 3).

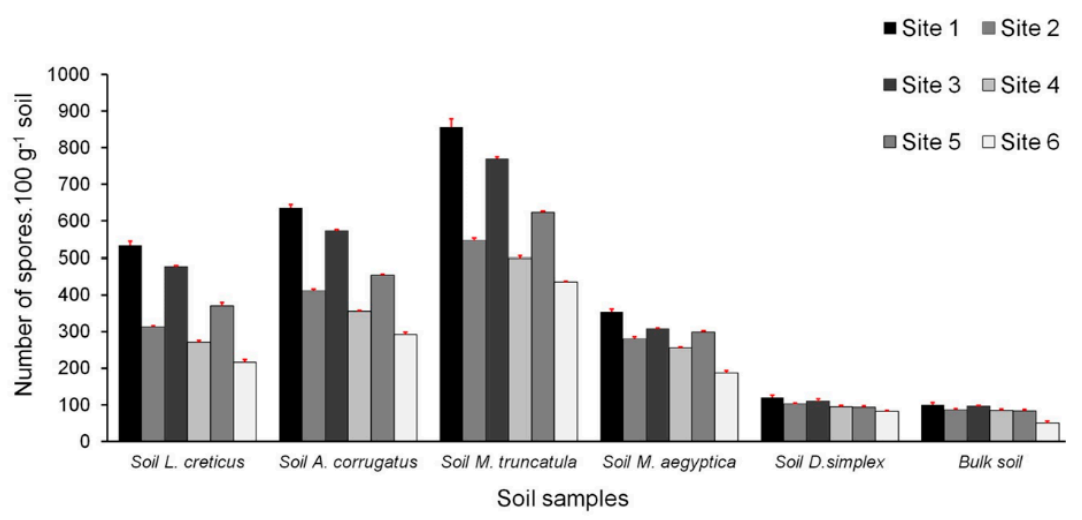

Figure 3. Distribution of AMF spores in the different rhizosphere soils. Data are reported as mean $( \pm \mathrm{SE})$ of three replicates per sample. 
There was a clear relationship between the intensity of root cortex AMF colonization (M\%), mycorrhizal frequency (F\%), and the density of AMF spores in the rhizospheres (Figures 2 and 3). Furthermore, the highest spore density was registered in the rhizosphere of the plant species with higher mycorrhiza frequency and intensity (M. truncatula).

\subsection{Effect of the Grazing Intensity on the Different AMF Parameters}

The grazing intensity strongly affected the mycorrhizal colonization and density of spores (Table 3), in accordance with the lowest values always registered, either for the plant mycorrhizal status or for AMF spore populations, in samples from sites outside the protected areas (Figures 2 and 3). This explains the negative effect of the grazing intensity on the different mycorrhizal parameters (Figure 4).

Table 3. Two-factor ANOVA analysis of the impact of grazing intensity on mycorrhizal parameters.

\begin{tabular}{ccc}
\hline \multirow{2}{*}{ Factor } & \multicolumn{2}{c}{ Grazing Intensity } \\
\cline { 2 - 3 } & F-Ratio & $p$-Value \\
\hline Mycorrhizal frequency $(\mathrm{F} \%)$ & 3.52 & $0.07^{\mathrm{ns}}$ \\
Mycorrhizal intensity $(\mathrm{M} \%)$ & 11.26 & $0.001^{* * *}$ \\
AMF spore density & 10.55 & $0.002^{* *}$ \\
\hline
\end{tabular}

$* * *$ Significant at $p<0.001, * *$ Significant at $p<0.01$, ns: non-significant.

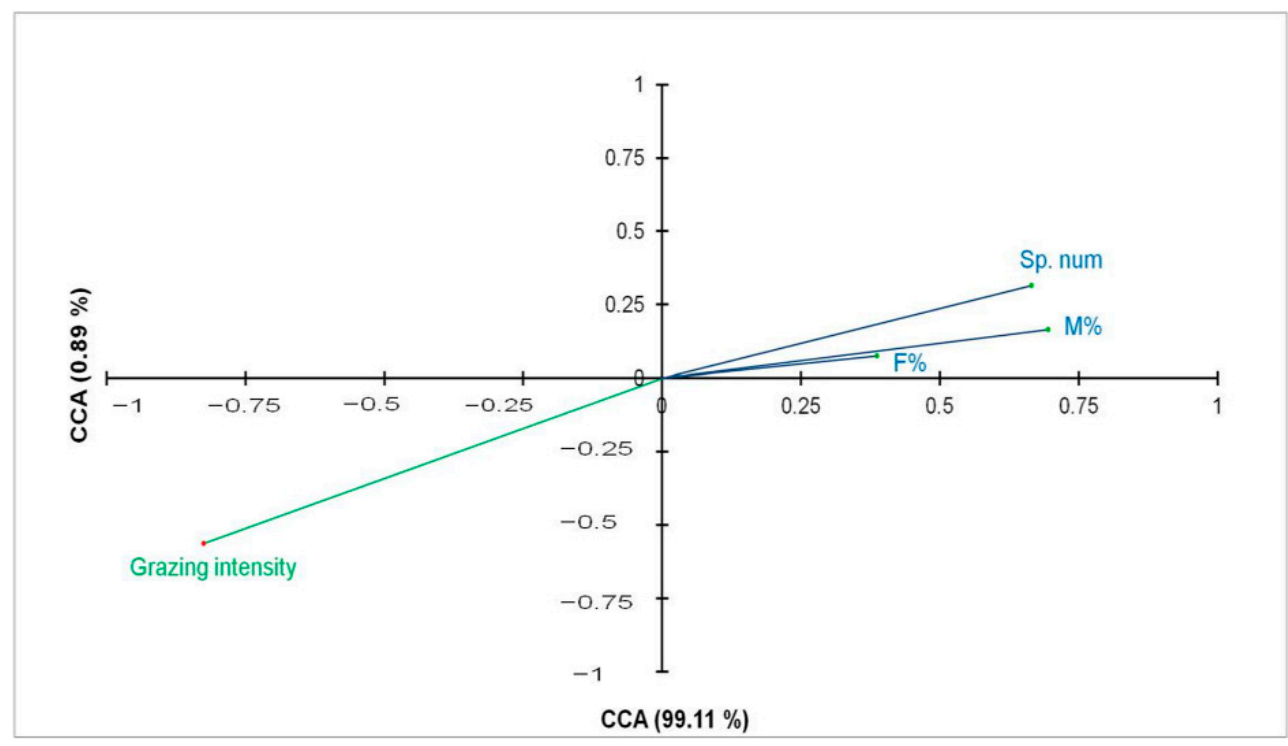

Figure 4. Results of a Canonical Correlation Analysis (CCorA) for the relationships between grazing intensity and AMF properties. Sp. num: number of spores; F\%: mycorrhizal frequency; M\%: mycorrhizal intensity.

\subsection{Effect of Soil Properties on the Different AMF Parameters}

According to the results of the Principal-component analysis (PCA) (Figure 5), the highest values of AMF colonization and number of spores were found in Site 1 at Bou-Hedma followed by Site 3 at Zarat. The major physical and chemical parameters of these sites (Org. Mat, E.c, Wat. Con, T.N) were in a strongly positive correlation with the different mycorrhizal properties. In contrast, the total phosphorus (T.P) available negatively affected all the mycorrhizal parameters and was considered a limited factor to these parameters (Figure 5). 


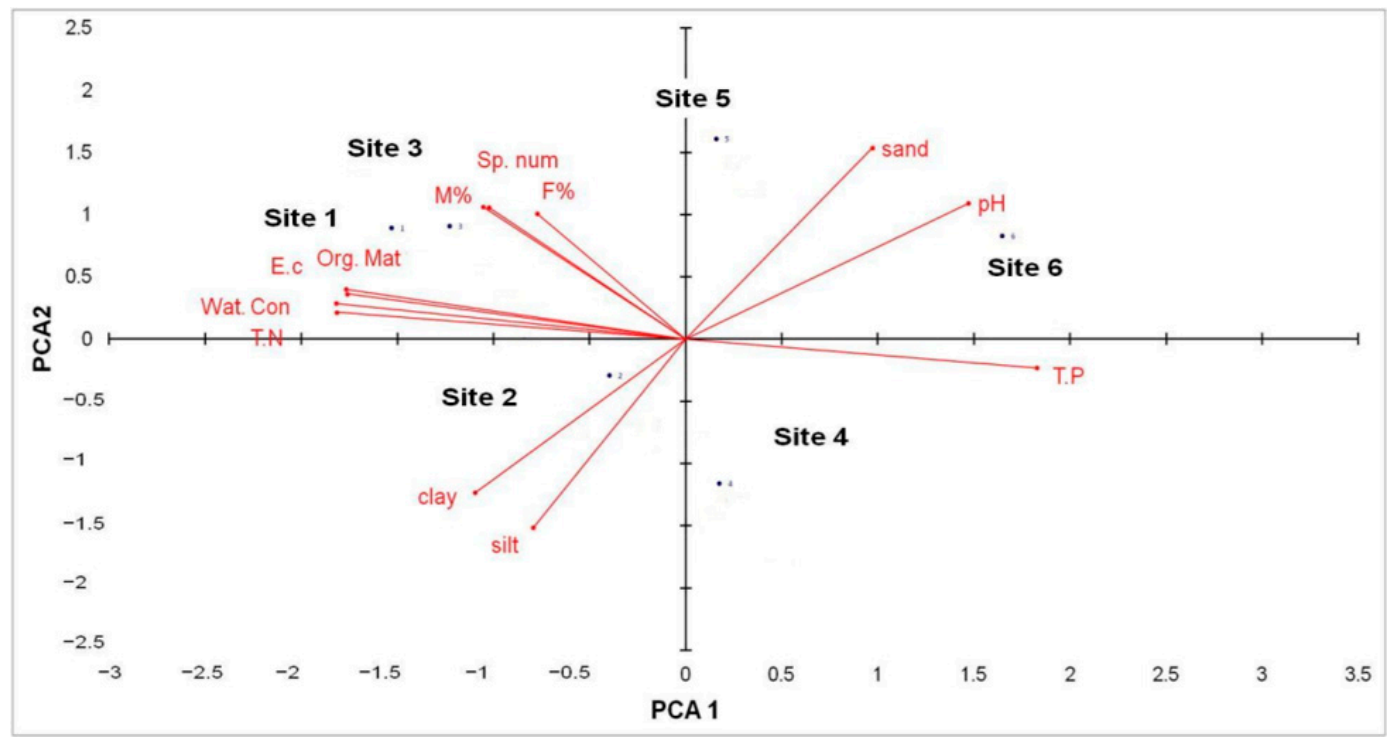

Figure 5. Results of a principal-component analysis (PCA) showing the relationships between soil properties and AMF parameters. E.c: electrical conductivity; T.N: total nitrogen; T.P: total phosphorus; Org. Mat: organic matter; Wat. Con: water content; Sp. num: number of spores; F\%: mycorrhizal frequency; $\mathrm{M} \%$ : mycorrhizal intensity.

\subsection{Microbiological and Biochemical Properties of the Soils and Impact of AMF on Soil Microbial Communities}

We found significant effects $(p<0.001)$ of the mycorrhizal plants on Cmic (Figure 6), this meaning that plants are affecting soil microbial biomass and consequently potential soil dynamics. The $\mathrm{Cmic}$ values were lower in bare areas (control soil) than in rhizosphere soils, the maximum values being recorded in the rhizospheres of the three Fabaceae plants M. truncatula, A. corrugatus and L. creticus. $\mathrm{Cmic}$ also markedly decreased in the intensively grazed sites (outside the protected areas), following the same trend of mycorrhizal frequency and intensity in root samples and of number of spores in rhizosphere soils (Figures 2, 3, 6 and 7).

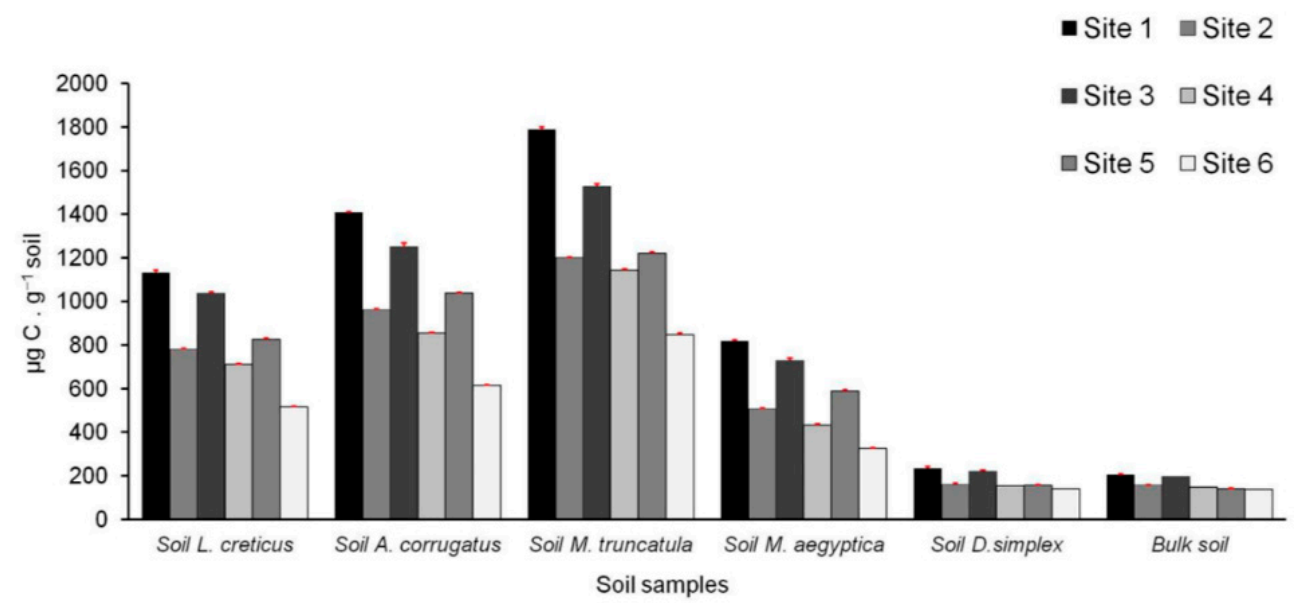

Figure 6. Microbial biomass carbon ( $\mathrm{Cmic}$ ) in the different sampled soils. Data are reported as mean $( \pm \mathrm{SE})$ of three replicates per sample. 


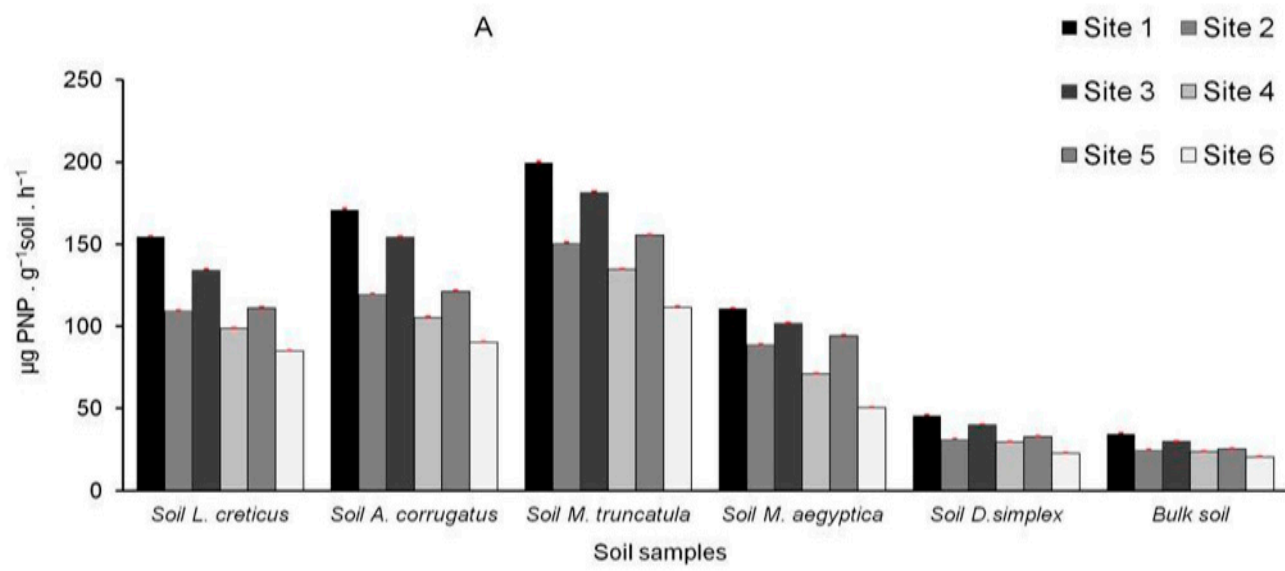

B
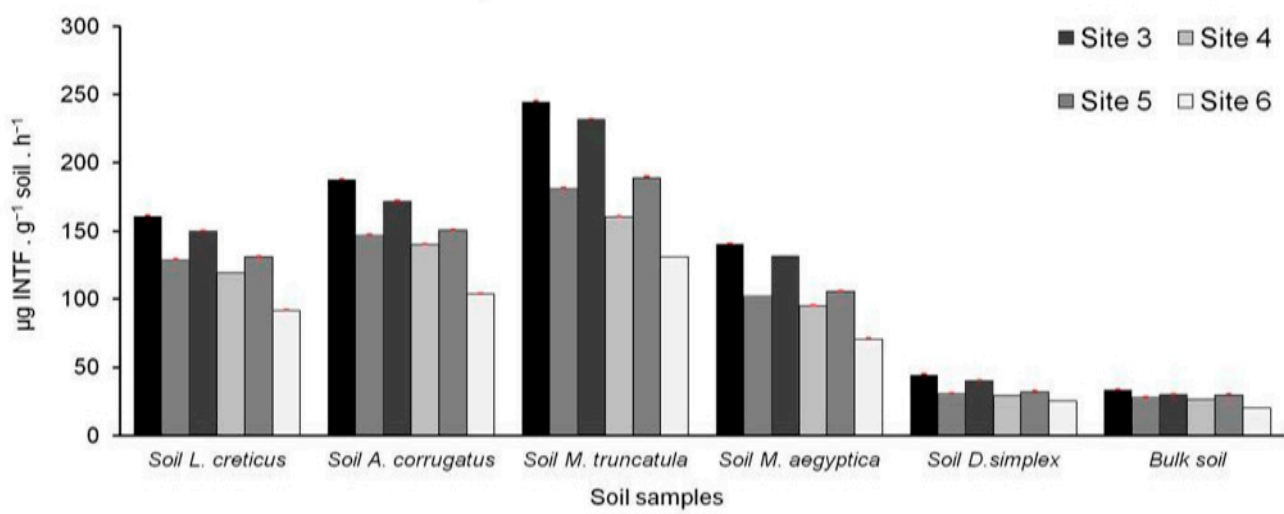

C

- Site 1 Site 2

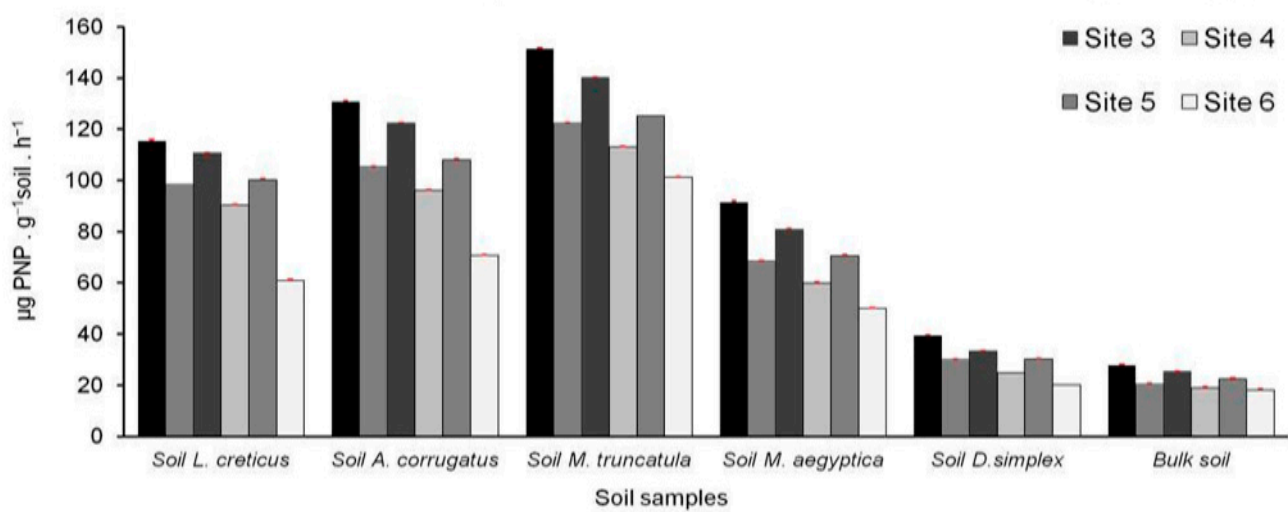

Figure 7. Phosphatase (A), dehydrogenase (B), $\beta$-glucosidase (C) activities in the studied soils. PNP: $p$ nitrophenol, INTF: iodonitrotetrazolium formazan. Data are reported as mean $( \pm \mathrm{SE})$ of three replicates per sample.

The highest activities of the three enzymes evaluated (phosphatase, dehydrogenase and $\beta$-glucosidase) (Figure 7) were observed in the rhizospheres of the three Fabaceae plants M. truncatula, A. corrugatus and L. halophilus, following the same trend of Cmic for each plant species and each site (Figure 6) as well as the values of mycorrhizal frequency and intensity and number of spores (Figures 2, 3 and 7), evidencing activities consistently greater in lightly grazed sites in comparison with those that were intensively grazed (Figures 2,3,7 and 8). The ANOVA analysis evidenced significant differences in these values. 


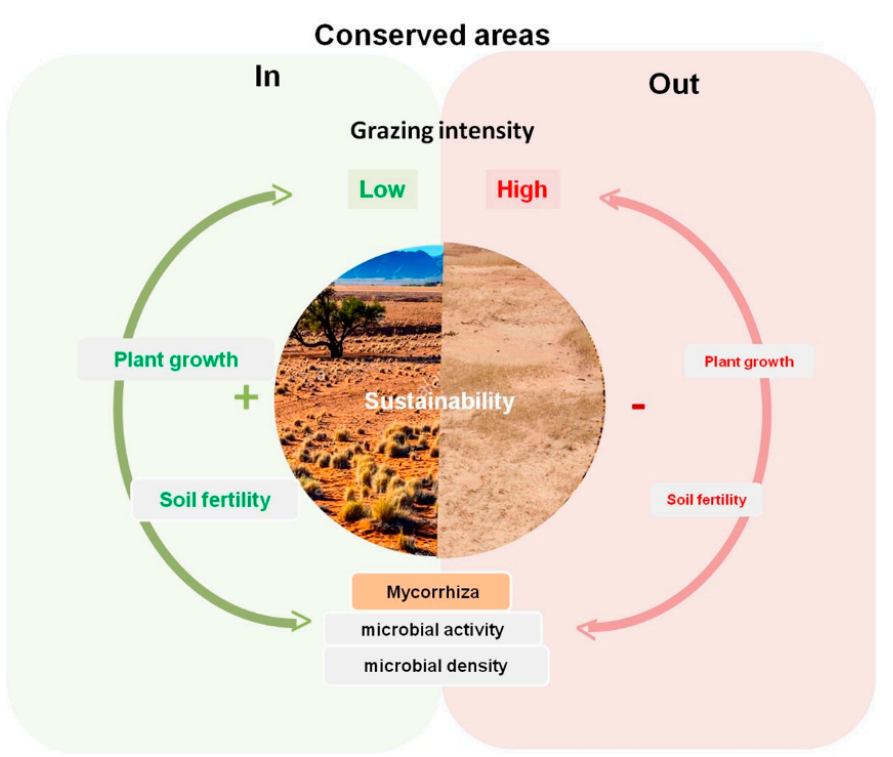

Figure 8. Schematic representation of the AMF effects on soil fertility and ecosystem stability under lightly grazed sites (inside the protected areas) versus intensively grazed sites (outside the protected areas), for arid Mediterranean ecosystems.

A clear relationship was observed between the AMF parameters (frequency and intensity of colonization of roots and number of AMF spores in the rhizosphere) and microbial activity (microbial biomass and enzyme activities) (Table 4, Figures S1 and S2). Based on the Pearson correlation coefficient, positive correlations with a highly significant value $(p<0.001)$ were observed between all AMF parameters ( $\mathrm{F} \%, \mathrm{M} \%$ and number of spores) and microbial activity (microbial biomass and enzyme activities: dehydrogenase, phosphatase and the $\beta$-glucosidase). A lower significant value $(p<0.05)$ was only observed in Site 6 (outside Oued Dkouk Natural Reserve) between the frequency of AMF colonization and two microbial parameters: microbial biomass and activity of $\beta$-glucosidase (Table 4).

Table 4. Pearson correlation coefficient between frequency of mycorrhization (F\%), intensity of mycorrhization (M\%) and density of AMF spores (Sp. num) and microbial activity expressed by microbial biomass (Cmic), phosphatase activity, dehydrogenase activity, and $\beta$-glucosidase activity.

\begin{tabular}{|c|c|c|c|c|c|c|}
\hline Conserved & reas & Title & Cmic & Phosphatase & Deydrogenase & $\beta$-Glucosidade \\
\hline \multirow{6}{*}{ Bou Hedma } & \multirow{3}{*}{ Site 1} & F\% & $0.93 * * *$ & $0.97 * * *$ & $0.95 * * *$ & $0.96^{* * *}$ \\
\hline & & $\mathrm{M} \%$ & $0.99 * * *$ & $0.99 * * *$ & $0.99 * * *$ & $0.98^{* * *}$ \\
\hline & & Sp. num & $0.93^{* * *}$ & $0.97^{* * *}$ & $0.95^{* * *}$ & $0.96^{* * *}$ \\
\hline & \multirow{3}{*}{ Site 2} & $\mathrm{~F} \%$ & $0.93^{* * *}$ & $0.97 * * *$ & $0.96^{* * *}$ & $0.96^{* * *}$ \\
\hline & & M\% & $0.98^{* * *}$ & $0.98^{* * *}$ & $0.99 * * *$ & $0.99 * * *$ \\
\hline & & Sp. num & $0.98^{* * *}$ & $0.96^{* * *}$ & $0.98^{* * *}$ & $0.98^{* * *}$ \\
\hline \multirow{6}{*}{ Zarat } & \multirow{3}{*}{ Site 3} & F\% & $0.95^{* * *}$ & $0.97^{* * *}$ & $0.96^{* * *}$ & $0.97^{* * *}$ \\
\hline & & $\mathbf{M} \%$ & $0.99 * * *$ & $0.98^{* * *}$ & $0.99 * * *$ & $0.98^{* * *}$ \\
\hline & & Sp. num & $0.95^{* * *}$ & $0.97 * * *$ & $0.96 * * *$ & $0.97^{* * *}$ \\
\hline & \multirow{3}{*}{ Site 4} & $\mathrm{~F} \%$ & $0.92 * * *$ & $0.97 * * *$ & $0.97^{* * *}$ & $0.96^{* * *}$ \\
\hline & & M\% & $0.96^{* * *}$ & $0.97 * * *$ & $0.99 * * *$ & $0.98^{* * *}$ \\
\hline & & Sp. num & $0.97^{* * *}$ & $0.96^{* * *}$ & $0.97^{* * *}$ & $0.95^{* * *}$ \\
\hline \multirow{6}{*}{ Oued Dkouk } & \multirow{3}{*}{ Site 5} & $\mathrm{~F} \%$ & $0.96^{* * *}$ & $0.97 * * *$ & $0.97^{* * *}$ & $0.97^{* * *}$ \\
\hline & & $\mathbf{M} \%$ & $0.99 * * *$ & $0.99 * * *$ & $0.98^{* * *}$ & $0.97^{* * *}$ \\
\hline & & Sp. num & $0.98^{* * *}$ & $0.97 * * *$ & $0.99 * * *$ & $0.98^{* * *}$ \\
\hline & \multirow{3}{*}{ Site 6} & $\mathrm{~F} \%$ & $0.90 *$ & $0.94^{* * *}$ & $0.95^{* * *}$ & $0.91 *$ \\
\hline & & M\% & $0.98^{* * *}$ & $0.98^{* * *}$ & $0.99 * * *$ & $0.98^{* * *}$ \\
\hline & & Sp. num & $0.98^{* * *}$ & $0.99 * * *$ & $0.97^{* * *}$ & $0.95^{* * *}$ \\
\hline
\end{tabular}

*** Significant at $p<0.001, *$ Significant at $p<0.05$. 
The results shown above, concerning the effect of grazing on AMF colonization (Table 3, Figure 4) and the impact of AMF on microbial communities and activities (Table 4, Figures S1 and S2), are summarized in Figure 8, which evidences the importance of AMF on soil functionality under arid Mediterranean ecosystems. Significant mycorrhizal colonization of roots was registered in lightly grazed sites, leading to high levels of microbial communities expressed by high values of biochemical activities. All these necessarily enhances soil fertility, better-adaptation and growth of plants and finally, in the stability of the ecosystem (Figure 8).

\section{Discussion}

Mediterranean arid and semi-arid ecosystems are characterized by high temperatures and drought for most of the year. These conditions limit plant establishment and growth and accelerate soil degradation and change microbial communities [1]. Mycorrhiza form communication pathways between plants and soil, influencing plant nutrient cycling, and restoring and maintaining soil fertility, thus influencing the microbial communities of the rhizosphere and extending the influence of plants to the soil. Several works emphasized the role of AMF in sustaining plant cover in semi-arid and arid ecosystems $[4,8,10]$ as is the case of the following Mediterranean conserved areas in Tunisia: Bou-Hedma National Park, Zarat protected area and Oued Dkouk Natural Reserve.

Under natural conditions, about $90 \%$ of the terrestrial plants are mycorrhized, and AMF are found in all climates and ecosystems [10]. Due to their role on plant nutrition and defense, and to the importance of the extra-radical mycelium in the establishment of biological networks, AMF are determinant for the establishment and sustainability of plant communities and environment functioning [7]. However, the diversity of the AMF community and the intensity of arbuscular mycorrhizal colonization of natural vegetation is dependent on the availability of AMF spores and the mycorrhizal dependency of the plant species [24,25], as well as on the soil structure and management [26]. All these statements agree with the results of the present study, which evidenced colonization by AMF for all the herbaceous species, except for the Cruciferaceae Diplotaxis simplex (Figure 2). This was not surprising since Cruciferaceae are usually recognized as non-mycorrhizal plants [27]. However, distinct AMF colonization rates and intensities were observed for each plant species, which may be related to different levels of mycorrhizal dependence [28], and/or the availability of AMF spores. Higher mycorrhization rates were observed in the legume species M. truncatula, A. corrugatus and L. creticus, which presented high levels of mycorrhizal intensity, independent of the sampled site (Figure 2). This may highlight their mycorrhizal dependency and high demand for phosphorus $(\mathrm{P})$ in comparison with plants from other families such as Poaceae [29].

In general, and particularly in semi-arid and arid ecosystem, AMF vary greatly with soil characteristics. Several biotic and abiotic factors may contribute to the distinct mycorrhizal intensities observed for the same plant species [30,31]. One abiotic factor that severely interferes with mycorrhization is the concentration of available phosphorus $[10,32,33]$. In the present study, soil phosphorus concentrations varied between sites, ranging from 7 to $15.3 \mathrm{ppm}$, and could explain the distinct mycorrhizal intensities observed for the same species in distinct sites (Figures 2 and 5), supporting that its availability is a crucial driver of mycorrhizal communities and activities [34].

Another factor frequently cited as responsible for lower levels of mycorrhiza formation is the availability of AMF spores, which is known to greatly vary in the ecosystems [35]. Sporulation in AMF occurs when the development of the mycelium begins to be limited by nutrients and is a highly carbon demanding process. This may explain why the number of AMF spores in the rhizosphere varies among plant species and, for the same plant species, among sites [36-38]. Apart from the rate of spore formation, the number of AMF spores in a soil also depends on the rates of spore germination and degradation [39]. As AMF are obligate biotrophs, the number of spores and propagules tends to be higher in the rhizosphere than in the bulk soil [12,40], and higher in the rhizosphere of plants with a higher intensity of AMF colonization (Figure 3). These differences are particularly evident in arid and semi-arid soils with high organic matter turnover rates and low organic matter content [41]. 
In low fertility soils, mycorrhiza are highways for nutrient and water transport, expanding the plant root system and the volume of soil exploited by the plant. However, similarly to roots, hyphae are leaky and lose nutrients into the hyphosphere, which will promote the development of selected microorganisms. In this context, it is expected that AMF play a crucial role in the biological characteristics of the rhizosphere [22,42] (Figure 6). The high values of Cmic observed in the rhizosphere soil of mycorrhizal plants imply that mycorrhiza contribute to improve the availability of carbon substrates to the microbial community of the rhizosphere [43,44]. These results support the hypothesis that AMF establish unique interactions with plant roots, conferring special characteristics to the rhizosphere [45], where several by product-based symbiosis and microbial loops may be assembled, contributing to improved carbon use efficiency. In this particular respect, the importance of AMF in promoting the development of the microbial community is confirmed by the low and comparable levels of microbial carbon observed in the soils without plant cover (control) and in the rhizosphere soil of the non-mycorrhizal plant D. simplex (Figure 6).

AMF increase the diversity of the carbon sources available to the microorganisms in the rhizosphere [46] - which is partly due to their nutritional mode; the excretion of catabolic enzymes to the surrounding medium, and to the direct access by the AMF to the plant carbon. Phosphatase and $\beta$-glucosidase are two of those catabolic enzymes, and their activities were in fact higher in the rhizosphere of the mycorrhizal plants than in that of the non-mycorrhizal plant studied or in the bulk soil (Figure 5). The importance of the soil microbial activity in association with several enzymes' activities was highlighted by the similarity in the activity patterns of the two hydrolytic enzymes (phosphatase and $\beta$-glucosidase) as well as of dehydrogenase, indicators of microbial activity [47], which can be inferred as being decreased under high grazing intensity (Figures S1 and S2).

At this point, it is clear that plant and AMF species are important modulators of rhizosphere characteristics (Figures 6-8). What is not clear is why biological indicators of soil characteristics are so distinct in the three sites outside the conserved areas. One key factor common to these sites may be limiting and related to mycorrhizal colonization. Grazing may affect mycorrhization (Table 3, Figure 4) directly in nutrient-limited ecosystems through a direct competition for carbon (Figure 8). Grazing was consistently associated with lower soil organic matter and increased P concentrations showing a strong impact on soil chemical properties, able to negatively influence mycorrhization in a direct way through the increase of $\mathrm{P}$ bioavailability. But in nutrient-limited ecosystems grazing per se may also affect mycorrhization (Table 3, Figure 4).

Plants are the primary producers of ecosystems, obtaining their biomass and energy from the carbon fixed by photosynthesis (Figure 8). Depending on the plant species and on the growth conditions, $20-50 \%$ of the newly photosynthetically fixed carbon may be transported to the roots and lost as rhizodeposition. In arid soils, this carbon is the main source of energy and biomass building material for the microbial community. Therefore, increasing grazing intensity decreases the carbon availability from plants and, consequently, also decreases the carbon available for mycorrhization [13,14]. An increase in grazing intensity has impacts on soil biological characteristics, with a significant decrease in the mycorrhizal intensity, as evidenced in the present study, for the three mycorrhizal plant species sampled in the sites outside the conserved areas (Table 3, Figure 5; Figure 8).

\section{Conclusions}

AMF is of vital importance in the arid Tunisian ecosystem, where soils are generally poor in organic matter and nutrients. High mycorrhization levels and high spore densities were revealed across the different sites, with particular incidence in the sites inside the conserved areas. Therefore, grazing intensity affected the potential beneficial influence of AMF on soil microbial processes. At this point, the importance of AMF to ecosystem dynamics is clear. What is not clear is how AMF are adapted to grazing intensity to allow ecosystem stability, particularly for situations that may be represented by the three sites outside the conserved areas. Therefore, future research should be focused on determining the ways through which AMF adapt to grazing intensity. This may be a key feature of 
ecosystem management, considering that AMF could be an important alternative for sustaining soil quality, and could be exploited as potential inoculants for rehabilitation and restoration programs in Mediterranean ecosystems.

Supplementary Materials: The following are available online at http://www.mdpi.com/1424-2818/12/6/234/s1, Figure S1: Linear regression to model the correlations between mycorrhizal proprieties (mycorrhizal frequency, mycorrhizal intensity, and number of spores) and the microbiological parameter microbial biomass carbon. The analyses included all available data: from the rhizospheres of the four plants and from bulk soil, Figure S2: Linear regression to model the correlations between mycorrhizal proprieties (mycorrhizal frequency, mycorrhizal intensity, and number of spores) and biochemical activities: phosphatase (in $\mu \mathrm{g} \mathrm{PNP.} \mathrm{g}^{-1}$ soil $^{-1}$ ), dehydrogenase $\left(\mu \mathrm{g}\right.$ INTF. $\mathrm{g}^{-1}$ soil. $\mathrm{h}^{-1}$ ) and $\beta$-glucosidase ( $\mu \mathrm{g}$ PNP. $\mathrm{g}^{-1}$ soil. $\mathrm{h}^{-1}$ ). The analyses included all available data: from the rhizospheres of the four plants and from bulk soil.

Author Contributions: Conceptualization, M.M. (Mohamed Mars); methodology, N.M.; validation, M.M. (Mosbah Mahdhi) and T.D.; formal analysis, N.M.; investigation, N.M.; data curation, N.M.; writing-original draft preparation, N.M.; writing - review and editing, C.C. and M.F.C.; visualization, C.C. and M.F.C.; project administration, M.M. (Mohamed Mars); funding acquisition, C.C. and M.F.C. All authors have read and agreed to the published version of the manuscript.

Funding: This work was supported by the Ministry of High Education and Research Development-Tunisia and by FCT/MCTES for the financial support to cE3c (project UIDB/00329/2020) and CESAM (projects UIDP/50017/2020+UIDB/50017/2020), through Portuguese national funds.

Acknowledgments: We thank the personal staff of Bou-Hedma National Park, of Zarat-Gabes Protected area and of the Natural reserve of Oued Dkouk, for facilities and support for root and soil sampling. Thanks, are also due to Francisco Caeiro for providing helpful comments and English revision.

Conflicts of Interest: The authors declare no conflict of interest.

\section{References}

1. Martínez-García, L.; Miranda, J.; Pugnaire, F.I. Impacts of changing rainfall patterns on mycorrhizal status of a shrub from arid environments. Eur. J. Soil Biol. 2011, 50, 64-67. [CrossRef]

2. Mahmoudi, N.; Cruz, C.; Mahdhi, M.; Mars, M.; Caeiro, M.F. Arbuscular mycorrhizal fungi in soil, roots and rhizosphere of Medicago truncatula: Diversity and heterogeneity under semi-arid conditions. PeerJ 2019. [CrossRef] [PubMed]

3. Mosbah, M.; Philippe, D.L.; Mohamed, M. Molecular identification of arbuscular mycorrhizal fungal spores associated to the rhizosphere of Retama raetam in Tunisia. Soil Sci. Plant. Nutr. 2018, 64, 335-341. [CrossRef]

4. Brundrett, M. Mycorrhizal associations and other means of nutrition of vascular plants: Understanding the global diversity of host plants by resolving conflicting information and developing reliable means of diagnosis. Plant Soil 2009, 320, 37-77. [CrossRef]

5. Van der Heijden, M.G.A.; Martin, F.M.; Selosse, M.A.; Sanders, J.R. Mycorrhizal ecology and evolution: The past, the present, and the future. New Phytologist. 2015, 204, 1406-1423. [CrossRef] [PubMed]

6. Barea, J.M.; Azcón, R.; Azcón-Aguilar, C. Mycorrhizosphere interactions to improve plant fitness and soil quality. Antonie van Leeuwenhoek. Inter. J. Gen. Mol. Microb. 2002, 81, 343-351.

7. Entry, J.A.; Rygiewicz, P.T.; Watrud, L.S.; Donnelly, P.K. Influence of adverse soil conditions on the formation and function of arbuscular mycorrhizas. Adv. Environ. Res. 2002, 7, 123-138. [CrossRef]

8. Smith, S.E.; Read, D.J. Mycorrhizal Symbiosis; Academic Press: San Diego, CA, USA, 1997.

9. Van Aarle, I.M.; Cavagnaro, T.R.; Smith, S.E.; Smith, F.A.; Dickson, S. Metabolic activity of Glomus intraradices in Arumand Paris-type arbuscular mycorrhizal colonization. New Phytologist. 2005, 166, 611-618. [CrossRef] [PubMed]

10. Smith, S.E.; Read, D.J. Mycorrhizal Symbiosis; Academic Press: San Diego, CA, USA, 2008.

11. Bago, B.; Vierheilig, H.; Piché, Y.; Ázcon-Aguilar, C. Nitrate depletion and $\mathrm{pH}$ changes induced by the extraradical mycelium of the arbuscular mycorrhizal fungus Glomus intraradices grown in monoxenic culture. New Phytol. 1996, 133, 273-280. [CrossRef] [PubMed]

12. Azcón-Aguilar, C.; Palenzuela, E.J.; Roldan, A.; Bautista, S.; Vallejo, R.; Barea, J.M. Analysis of the mycorrhizal potential in the rhizosphere of representative plant species from desertification-threatened Mediterranean shrub lands. Appl. Soil Ecol. 2003, 22, 29-37. [CrossRef] 
13. Barto, E.K.; Rilling, M.C. Does herbivory really suppress mycorrhiza? A meta-analysis. J. Ecol. 2010, 98, 745-753. [CrossRef]

14. Mendoza, R.; Cabello, M.; Anchorena, J.; García, M.L. Soil parameters and host plants associated with arbuscular mycorrhizae in the grazed Magellanic steppe of Tierra del Fuego. Agric. Ecosyst. Environ. 2011, 140, 411-418. [CrossRef]

15. Raiesi, F.; Asadi, E. Soil microbial activity and litter turnover in native grazed and ungrazed rangelands in a semiarid ecosystem. Biol. Fertil. Soil 2006, 43, 76-82. [CrossRef]

16. Liao, J.D.; Boutton, T.W. Soil microbial biomass response to woody plant invasion of grassland. Soil Biol. Biochem. 2008, 40, 1207-1216. [CrossRef]

17. Phillips, J.M.; Hayman, D.S. Improved procedure for clearing roots and staining parasitic and vesicular arbuscular mycorrhizal fungi for rapid assessment of infection. Trans. Br. Mycol. Soc. 1970, 55, 158-161. [CrossRef]

18. Gerdemann, J.W.; Nicolson, T.H. Spores of mycorrhizal Endogone species extracted by wet sieving and decanting. Trans. Br. Mycol. Soc. 1963, 46, 235-244. [CrossRef]

19. AFNOR. Recueil de normes françaises, qualité des sols, méthodes d'analyses, 1st ed.; Association française de normalisation (Afnor): Paris, France, 1987.

20. Naanaa, W.; Susini, J. Méthodes d'analyse physique et chimique des sols. ES 252, Direction des Sols; Ministère de l'Agriculture: Tunis, Tunisie, 1988.

21. Amato, M.; Ladd, J.N. Assay for microbial biomass based on ninhydrin-reactive nitrogen in extracts of fumigated soils. Soil Biol. Biochem. 1988, 20, 107-114. [CrossRef]

22. Caravaca, F.; Alguacil, M.; Torres, P.; Roldán, A. Plant type mediates rhizospheric microbial activities and soil aggregation in a semiarid Mediterranean salt marsh. Geoderma 2005, 12, 338-375. [CrossRef]

23. Garcia, C.; Hernandez, T.; Costa, F. Potential use of dehydrogenase activity as an index of microbial activity in degraded soils. Commun. Soil Sci. Plan. 1997, 28, 123-134. [CrossRef]

24. Zhu, Y.G.; Laidlaw, A.S.; Christie, P.; Hammond, M.E. The specificity of arbuscular mycorrhizal fungi in perennial ryegrass, white clover pasture. Agric. Ecosyst. Environ. 2000, 77, 211-278. [CrossRef]

25. Duponnois, R.; Founoune, H.; Masse, D.; Pontanier, R. Inoculation of Acacia holosericea with ectomycorrhizal fungi in a semi-arid site in Senegal: Growth response and influences on the mycorrhizal soil infectivity after 2 years plantation. For. Ecol. Manag. 2005, 207, 351-362. [CrossRef]

26. Lekberg, Y.; Koide, R.T.; Rohr, J.R.; Aldrich-Wolfe, L.; Morton, J.B. Role of niche restrictions and dispersal in the composition of arbuscular mycorrhizal fungal communities. J. Ecol. 2007, 95, 95-105. [CrossRef]

27. Muchovej, R.M. Importance of Mycorrhizae for Agricultural Crops, SS-AGR-170; Agronomy Department, Florida Cooperative Extension Service; Institute of Food and Agricultural Sciences, University of Florida: Gainesville, FL, USA, 2004.

28. Strullu, D.G. Les mycorhizes des arbres et des plantes cultivées; Techniques et Documentation Lavoisier: Paris, France, 1991.

29. Bagayogo, M. Site Specific Effects of Cereals/Legume Rotations in West Africa: Soil Mineral Nitrogen, Mycorrhizae and Nematodes; Verlag Graner: Stuttgard, Germany, 1999.

30. Henriques, R.P.; Hay, J.D. The plant communities of a foredune in southeastern Brazil. Can. J. Bot. 1998, 76, 1323-1330.

31. Mahesh, V.; Selvaraj, T. Occurrence and distribution VA mycorrhizal fungi in the soils polluted with Tannery Effluent. Adv. Biotech. 2008, 8, 34-36.

32. Dickson, S.; Smith, S.E.; Smith, F.A. Characterization of two arbuscular mycorrhiza fungi in symbiosis with Allium porum: Colonization, plant growth and phosphate uptake. New Phytol. 1999, 144, 163-172. [CrossRef]

33. Bouamri, B.; Dalpé, Y.; Serrhini, M.N.; Bennani, A. Arbuscular Mycorrhizal fungi species associated with rhizosphere of Phoenix dactylifera L. in Morocco. Afr. J. Boitech. 2006, 5, 510-516.

34. Liu, W.; Zhang, Y.; Jiang, S.; Deng, Y.; Christic, P.; Murray, P.J.; Li, X.; Zhang, J. Arbuscular mycorrhizal fungi in soil and roots respond differently to phosphorus inputs in an intensively managed calcareous agricultural Soil. Sci. Rep. 2016, 6, 1-11. [CrossRef] [PubMed]

35. Li, L.; Yang, A.; Zhao, Z. Seasonality of arbuscular mycorrhizal symbiosis and dark septate endophytes in grassland site in Southwest China. Microbial. Ecol. 2005, 54, 367-373.

36. Houngnandan, P.; Yemadje, R.G.; Kane, A.; Boeckx, P.; Van Cleemput, O. Les glomales indigènes de la forêt claire à Isoberliniadoka (Craib et Stapf) à Wari-Maro au centre du Bénin. Tropicultura 2009, 27, 83-87. 
37. Sghir, F.; Chliyeh, M.; Kachkouch, W.; Khouader, M.; OuazzaniTouhami, A.; Benkirane, R.; Douira, A. Mycorrhizal status of Olea europaea ssp. Oleaster in Morocco. J. Appl. Biosci. 2013, 61, 4478-4489. [CrossRef]

38. Al-Areqi, A.N.; Chliyeh, M.; Sghir, F.; Ouazzani, A.; Benkirane, R.T.; Douira, A. Diversity of Arbuscular mycorrhizal fungi in the rhizosphere of Coffea Arabica in the Republic of Yemen. J. Appl. Biosci. 2013, 64, 4888-4901. [CrossRef]

39. Gemma, J.N.; Koske, R.E.; Carreiro, M. Seasonal variation in spore abundance and dormancy of Gigasporagigantea in Mycorrhizal inoculum potential of a dune Soil. Mycologia 1989, 80, 211-216. [CrossRef]

40. Lovelock, C.E.; Andersen, K.; Morton, J.B. Arbuscular mycorrhizal communities in tropical forests are affected by host tree species and environment. Oecologia 2003, 135, 268-297. [CrossRef] [PubMed]

41. Mohammad, M.J.; Hamad, S.R.; Malkawi, H.I. Population of arbuscular mycorrhizal fungi in semi-arid environment of Jordan as influenced by biotic and abiotic factors. J. Arid Environ. 2003, 53, 409-417. [CrossRef]

42. Cruz, R.E.; Garcia, M.U. Nitrogen fixation and mycorrhizae in acacias on degraded grasslands. In Tropical Acacias in East Asia and the Pacific; Kamiset, A., Taylor, D.A., Eds.; Winrock Intenational Institute for Agriculture Research: Bangkok, Thailand, 1992; pp. 59-71.

43. Böhme, L.; Langer, U.; Böhme, F. Microbial biomass, enzyme activities and microbial community structure in two European long-term field experiments. Agric. Ecosyst. Environ. 2005, 109, 141-152. [CrossRef]

44. Fließbach, A.; Oberholzer, H.R.; Gunst, L.; Mäder, P. Soil organic matter and biological soil quality indicators after 21 years of organic and conventional farming. Agric. Ecosyst. Environ. 2007, 118, 273-274. [CrossRef]

45. Dennis, P.G.; Miller, A.J.; Hirsch, P.R. Are root exudates more important than other sources of rhizodeposits in structuring rhizosphere bacterial communities? Microbial. Ecol. 2010, 72, 313-327. [CrossRef] [PubMed]

46. Rillig, M.C. Arbuscular mycorrhizae, glomalin and soil quality. Can. J. Soil Sci. 2004, 84, 355-363. [CrossRef]

47. Nannipieri, P.; Kandeler, E.; Ruggiero, P. Enzyme activities and microbiological and biochemical processes in Soil. In Enzymes in the Environment; Activity, Ecology and Applications; Burns, R.G., Dick, R.P., Eds.; Marcel Dekker: New York, NY, USA, 2002; pp. 1-33.

(C) 2020 by the authors. Licensee MDPI, Basel, Switzerland. This article is an open access article distributed under the terms and conditions of the Creative Commons Attribution (CC BY) license (http://creativecommons.org/licenses/by/4.0/). 